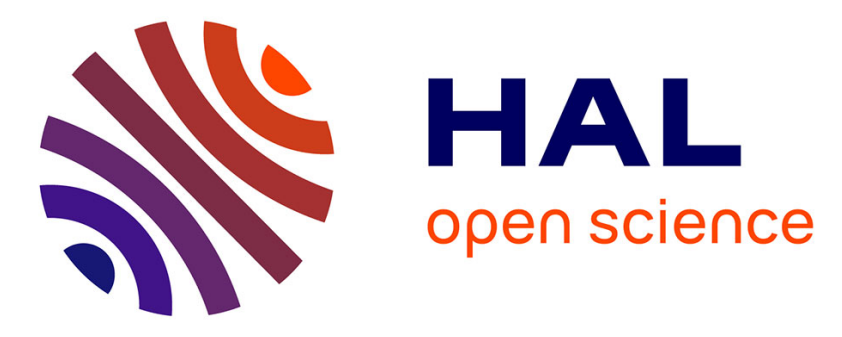

\title{
Comprehensive Improvement of Industrial Energy Efficiency: Pilot Case in a European Rolling Stock Factory
}

Nils Weinert, Rafael Fink, Christian Mose, Friedrich Lupp, Florian Müller, Jan Fischer, Ingo Bernsdorf, Alessandro Cannata

\section{To cite this version:}

Nils Weinert, Rafael Fink, Christian Mose, Friedrich Lupp, Florian Müller, et al.. Comprehensive Improvement of Industrial Energy Efficiency: Pilot Case in a European Rolling Stock Factory. IFIP International Conference on Advances in Production Management Systems (APMS), Sep 2014, Ajaccio, France. pp.334-341, 10.1007/978-3-662-44736-9_41 . hal-01387891

\section{HAL Id: hal-01387891 \\ https://hal.inria.fr/hal-01387891}

Submitted on 26 Oct 2016

HAL is a multi-disciplinary open access archive for the deposit and dissemination of scientific research documents, whether they are published or not. The documents may come from teaching and research institutions in France or abroad, or from public or private research centers.
L'archive ouverte pluridisciplinaire HAL, est destinée au dépôt et à la diffusion de documents scientifiques de niveau recherche, publiés ou non, émanant des établissements d'enseignement et de recherche français ou étrangers, des laboratoires publics ou privés. 


\title{
Comprehensive improvement of industrial energy efficiency: Pilot case in a European rolling stock factory
}

\author{
Nils Weinert ${ }^{1}$, Rafael Fink ${ }^{1}$, Christian Mose ${ }^{1}$, Friedrich Lupp ${ }^{1}$, Florian Müller ${ }^{1}$, \\ Jan Fischer ${ }^{1}$, Ingo Bernsdorf ${ }^{2}$, Alessandro Cannata ${ }^{1}$ \\ ${ }^{1}$ Siemens AG Corporate Technology, Munich, Germany \\ \{nils.weinert, rafael.fink, christian.mose, friedrich.lupp, mueller \\ florian.ext, jan.fischer.ext, alessandro. cannata\} @siemens.com \\ ${ }^{2}$ Siemens AG Corporate Technology, Berlin, Germany \\ ingo.bernsdorfesiemens.com
}

\begin{abstract}
Energy and resource efficiency requires more suitable approaches to be consistently implemented in industry. Factories are more complex systems than residential or commercial buildings; in industrial domain, improvements for energy efficiency require measures that are difficult to be identified and that vary from building to manufacturing processes fields. This paper presents a comprehensive approach to systematically address industrial energy efficiency improvement. The approach has been developed and tested at a European rolling stock manufacturer. Insights from the pilot case presented confirm that this holistic view helps properly address energy efficiency in industrial domain.
\end{abstract}

Keywords: eco-factory, rolling stock manufacturing, energy efficiency.

\section{Introduction}

Manufacturing is one of the main consumers of global primary energy consumption and producer of related emissions. Improvement of energy efficiency in factories is a key driver to support the achievement of European 20/20/20 goals. Hence, industry has to rethink current approaches about design and management of manufacturing systems, to take a significant step towards energy efficient factories.

However the task is challenging, since factories are complex systems made of interacting elements such as people, production assets, material handling equipment, building service equipment, etc. A holistic approach which, moving away from local optimization, considers the factory as a whole has been developed within EMC $^{2}$ Factory, an on-going FP7-European Research project (www.emc2-factory.eu).

To show its industrial applicability, the approach has been tested in a real case, a European rolling stock factory several measures to improve energy efficiency have been identified and developed, of which the most relevant and impactful are presented in this paper.

The approach is briefly introduced in section 2; section 3 and 4 describe the pilot case and the identified measures; section 5 includes final conclusions.

adfa, p. 1, 2011.

(C) Springer-Verlag Berlin Heidelberg 2011 


\section{Approach adopted}

$\mathrm{EMC}^{2}$-Factory project aims at developing new solutions for planning and operating eco-efficient factories, as well as using existing methods and tools combining them in a more effective way. An integrated view has been adopted in the project to prevent problem shifting due to the mentioned complex system interconnections, e.g. from production to technical building services. This integrated view fully considers all the components in a factory and their reciprocal influence on each other. Solutions (both developed within $\mathrm{EMC}^{2}$-Factory and available externally) for this variety of fields are very diverse and end up in a high-number of alternatives that the decision maker can choose. Moreover, since factories are significantly different for every specific case, this complicates the decision making for energy efficiency improvement in the individual industrial case.

Hence, a method to identify the case-specific measures has been developed. This method, of which details are published in [1], helps the user to systematically address the most impactful measures and optimize energy efficiency and lean production for the overall factory system by selection of appropriate solutions for a specific discrete production environment. Solutions, in this context, are for instance technologies, organizational principles and frameworks or software tools developed in the $\mathrm{EMC}^{2}$ Factory project by all partners, in addition to existing and established approaches from academia and industry. The methodology was tested against the pilot described in the following chapter - an existing Siemens AG rail car factory. The methodology is based on two phases with six sequential process steps. A numerically ranked set of applicable solutions is derived by narrowing down possible solutions from a larger set and thus improving the proposed ranking stepwise.

In the first phase, the user specifies preferences for certain types of solutions by specifying criteria values that differentiate between solution elements. Criteria are e.g. the applicable factory level, the life cycle phase or the problem solving phase. Each criterion is then numerically weighted against one another by the user.

In the second phase, a hierarchical, class-based factory model is set up, mainly describing the physical elements of a factory. This model is used in the extended energy value stream analysis (EEVSA) [2] to store the properties of the physical elements required for deriving the values of the EEVSA. The main goal of the EEVSA is to map the total energy consumption of a factory to individual process chains/valuestreams, taking all peripheral systems into account. Based on the KPIs coming from the EEVSA, a set of certain Energy Drivers can be ranked in order to differentiate sources for the total energy consumption of processes. In the next step the ranked Energy Drivers are mapped to the so-called Design Parameters, returning a ranked set of these. Design Parameters are levers of a factory that can usually be utilized to improve energy efficiency or lean performance (e.g. factory layout, long-term production schedule, machine control). Since the correlation between Design Parameters and the solutions can be numerically approximated, these solutions can be ranked in a subsequent mapping step by matrix multiplication. The ranked solutions are then selected for application in a final step, using Total Cost of Ownership (TCO) methodology and cross-impact analysis. 


\section{$3 \quad$ Pilot case description and motivation}

The selected pilot case is a Siemens AG rolling stock manufacturing site located in Vienna. It produces rail vehicles of stainless steel or of aluminium for Metros, Coaches and Light Rail. Several processes are there performed, such as machining, grinding, joining, coating, and final assembly in a shop floor area of $63000 \mathrm{~m}^{2}$. Before this research activity started, the site already addressed the topic of energy and resource efficiency with different projects on building renovation (insulation, ventilation systems, etc.), a new surface treatment center, and product design improvement from product life cycle perspective (e.g. lighter materials to consume less energy during the use phase of the trains, use of recyclable material), however the holistic factory perspective adopted in this project was not yet part of the considerations.

In order to show impact of the developed approach on energy efficiency, the pilot has been focused on a single building of the site. In this building, the main train components such as undercarriages, roofs and sides of a train car are manually grinded and manually and/or automatically welded. Moreover in the same building two machining centres are available for pre- and post-welding processes. With an area ca. $4500 \mathrm{~m}^{2}$, the building was chosen for three reasons:

- Representative: It includes typical manufacturing processes of train production;

- Relevant: It shows complex material flow and interaction among processes;

- Challenging: It was recently improved from energy perspective such as air heat exchangers, building insulation, and air doors. Hence, further improvement requires going beyond state-of-the-art technologies and approaches.

\section{Overview of measures analysed}

For the investigated building and the affected part of the metro car's value stream, the solution finding process was applied as described in chapter two. First the as-is analysis has been performed gathering both energy and production-related information.

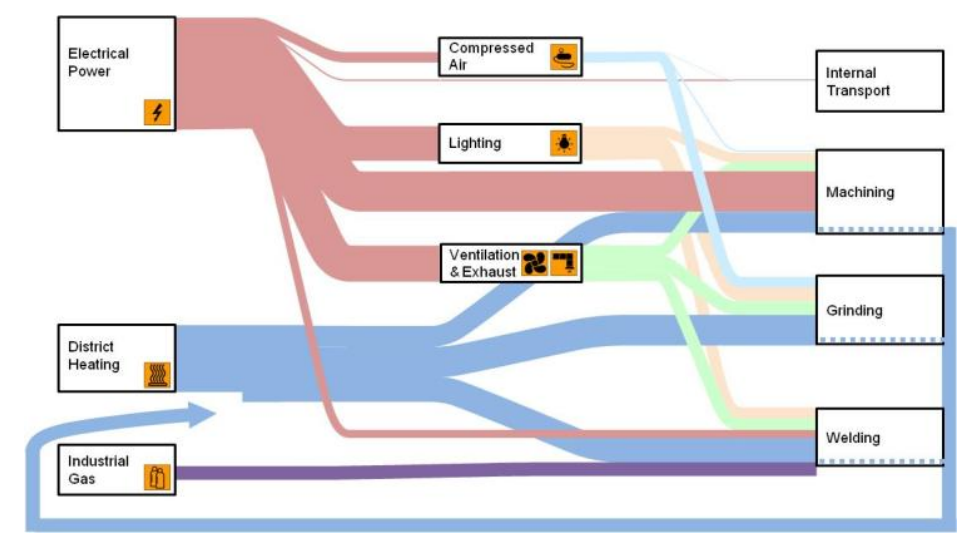

Fig. 1. Representation of energy sankey diagram performed for the pilot case 
Based on one-time measurements, several shop floor visits and available production data the required information to set up the hierarchic factory model and to derive the extended energy value stream could be acquired. The total energy consumption of the building (visualized as an Energy Sankey diagram in Fig. 1), indicated high consumption of peripheral hardware like lighting, heating and ventilation among others.

Using the results of the EEVSA, the solution finding process was performed with several iteration loops. Each iteration loop was defined with different user preferences according to the momentary step in the problem solving process and the related focus of application (e.g. analysis vs. solution phase, process vs. process-chain perspective). Fig. 2 depicts the results of an exemplary iteration loop, targeting the analysis phase and the value stream process utilizing the biggest electrical consumer.

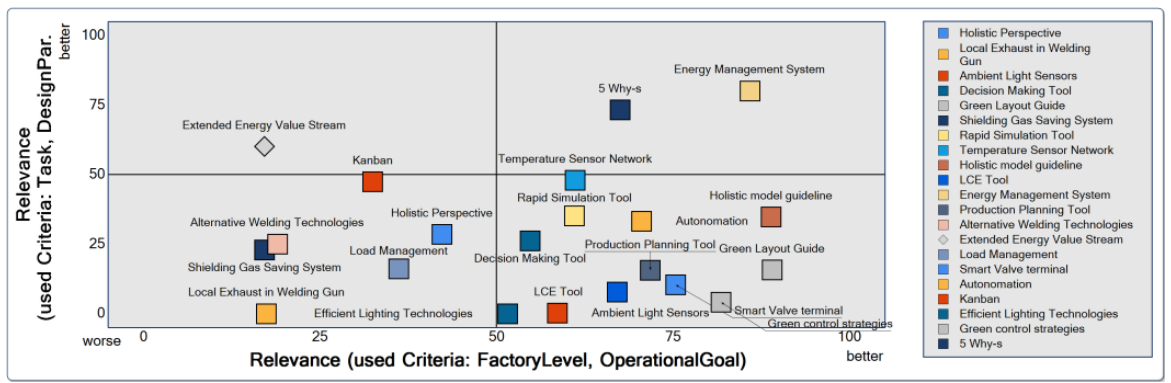

Fig. 2. Results of exemplary iteration cycle of solution finder

After several iterations, the solution finder indicated the biggest potential for energy management, production planning, alternative welding-technologies and layout.

\subsection{Energy Transparency and Management System}

As one of the common principles in engineering, knowledge gained from transparency is often seen as a prerequisite for improvement. Following this maxim, as a first step certain relevant production entities have been energetically measured using onetime measurements. First insights on energy consumption and distribution were used as input for the solution finder [3].

One-time measurements are sufficient for providing a basic knowledge on the consumption in a steady application, but in a dynamic environment like present in production continuous monitoring is required to detect shortages. Beyond developing transparency, actual management of energy consumption becomes possible, leading to the decision to implement an Energy Management System (EMS) for the investigated building. The system consists of several measuring points for electrical energy and pressurized air. Using an industrial PC, measured consumptions are monitored automatically in real time, generating signals for control measures like machine standby opportunities or air leakage detection. The architecture (Fig. 3) is designed for later enhancements, e.g. automated interventions in those cases, or for being integrated in an overall, factory-wide Energy Management System as required, e.g. by ISO 50001 or by future integration in Smart Grid environment. 


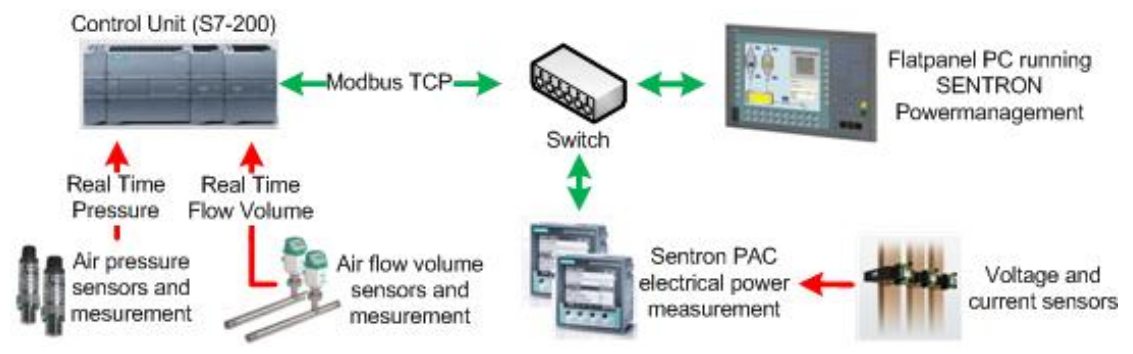

Fig. 3. Energy Management System - concept

\subsection{Production Planning Tool}

Depending on the range and the complexity of the goods produced production planning can be a difficult task. Presumably that is one of the reasons why most contributions from scientific literature and scheduling principles applied in practice often just focus on single economic aspects like the adherence to delivery dates or the minimization of the make-span. Yet, production planning is a highly multi-objective task, in general. If, for instance, it is not accounted for potentials to improve energy efficiency during the planning process, these potentials will not be tapped in the production execution phase, either.

In the following some examples for levers are provided to include the aspect of energy efficiency into the production planning process:

- A minimization of non-value-adding work (e.g. setup and transportation activities) helps to avoid the wasting of time and energy. Additionally it reduces the logistic complexity of the production process.

- An appropriate choice of the utilized production machines and modes can help to reduce the energy cost without harming other planning objectives (e.g. if alternative machines are available or velocity can be regulated).

- Load balancing and the minimization of peak loads can contribute to significantly lower energy costs, if peak-load is charged and the production process is very energy intensive.

- A smart production organization (e.g. synchronization of individual shift systems) can help to reduce energy costs related to TBS like air conditioning, lighting, heating and exhaustion systems, etc.

- The anticipation of applied control strategies (which e.g. decide if and when machines are switched off during idle periods) can lead to a smoother course of production and therefore contribute to improve energy efficiency.

Based on this list of levers and the circumstances in the industrial pilot case, a multicriteria production planning software tool was developed and implemented within the $\mathrm{EMC}^{2}$-Factory project. With the help of that tool production planners can now simultaneously optimize the production process with respect to different KPIs like adherence to delivery dates or the energy consumption. Tradeoffs between these KPIs can now be quantified by calculating and evaluating not just one single solution but a set 
of alternative non-dominated schedules. The algorithmic approach is based on a multi-start priority rule based schedule construction heuristic. For details on the algorithmic concept that has been realized in the software tool see [4].

\subsection{Alternative Welding Technologies}

In a factory, the total energy consumption is significantly higher than the actual energy required for the main, value adding manufacturing steps. One reason for this is the effectiveness of the processes as well as secondary processes that are required to perform the core process. Furthermore, a complete process chain includes several preand post-processes consuming energy themselves, e.g. milling a work piece as preparation for a joining process. Additionally large variety of secondary energy consumers is required, including maintenance and transport operations and technical building services (TBS) [5].

All of these pre-, post- and secondary processes are consuming energy only for enabling the actual value adding manufacturing steps. Consequently, in the design of a process chain, it is not sufficient to focus on the main steps only, but rather to investigate energetic demands more comprehensive to achieve an overall optimum.

For doing so, process designers need to have the possibility to compare alternative process chains by providing an indicator, including the energy demand of all relevant primary and secondary consumers. This key element has been developed as a processdependent, normative energy indicator. Focussing on welding processes as the prevalent manufacturing process in the rail car industry, the specific energy demand per welded length is used. The indicator was defined as the accumulated energy over all considered process states and the whole production sequence, divided by the total length of weld created in that time [6]. Dominant factors influencing the indicator are found within the areas of:

- A particular process technology (e.g. GMAW or FSW);

- Particular process parameters for the observed work piece;

- Auxiliary systems implemented in the observed manufacturing equipment;

- Amount of non-productive time and associated energy demand on the equipment;

- Organizational influence by equipment's productive - non-productive time ratio;

- Organizational influence through the load of the equipment.

The approach introduced was applied in the Siemens plant to investigate alternative welding processes. Essential results are that within welding processes for aluminium, Friction Stir Welding (FSW) has an advantage over Gas-Metal-Arc Welding (GMAW) regarding its energy demand of the main process and even more for secondary consumptions - mainly caused by the fume emission of GMAW and the required exhaust systems - emphasizing the need to explicitly consider these in process chain design. However, a short term change of process chains for existing products is difficult to realize due to reasons of approved designs and processes, etc. Anyways, now the data is available to consider this advantage for future product designs. 


\subsection{Layout Reconfiguration}

The production system layout is of special interest for an energy efficient design of buildings. A production system is the surface organization and the area where production environment conditions (e.g. illumination, temperature) interact with the equipment. While general planning guidelines (e.g. minimal floor load zones) are state of the art in planning, the planning of elements like layout, TBS and disposal infrastructure across interfaces requires to enforce communication, collaboration and a faster decision making. Additional multidisciplinary experts need to provide knowledge and analytical methods together if the planning activity is properly designed.

A workshop-based green layout planning method was developed to position machines and equipment with environmental aspects in mind (for details see [7]). Concerning the pilot case three alternative layouts were developed that can be beneficial:

- Separation of welding and machining: Welding and machining of metal parts requires filtering and exhaust ventilation of a different kind. If welding and machining operations would be locally separated smaller and better designed TBS for one specific function could be used. A local decentralized exhaust system would be another option to avoid a central TBS system completely. Security and process barriers caused by electrical conductibility of car bodies make this an unrealistic option.

- Isolated preheating zone for car body: Because of quality reasons the car body needs to have a certain temperature to be processed so a preheating time up to 24 hours can be necessary in the facility. Therefore additional heat will be supplied through the radiators. Preheating next to surface treatment to use waste heat from there would make the heating system consume less energy and reuse otherwise wasted thermal sources.

- Discrete milling area: Despite local chip disposal, coolant system and workplace lighting the two milling centers are on the both outsides of the building with machining and welding operations. If the milling would be separated, there would be no exhaust and TBS system required. Additional transport way and handling effort has to be considered for the production planning.

Since cost for a building and TBS change are disproportionately high the implications have to be considered in the future building (re-)planning of the site. Nevertheless they are general principles, whose implications from environmental side can be easily identified through layer evaluation (for details on this approach see [8]).

\section{$5 \quad$ Discussion and conclusions}

The proposed approach started from creating transparency with an energy management system and covered different areas normally assessed only for productionrelated performance (production planning, substitution of processes and layout reconfiguration). The solutions highlighted from the approach are highly interdisciplinary and they address the challenge of energy efficiency from different perspectives.

Two transversal remarks came out from testing the approach: 
1. To address energy efficiency, the complete system made of production machines, processes, TBS, and building shell has to be analysed as entity. For example, the improvement of the direct energy requirement for welding process (local optimization), can have less impact than the reduction of energy for auxiliary systems (fume exhaust) or to the substitution of process technologies to avoid fumes.

2. Although countless measures for energy efficiency improvement are available, each case has specific features and issues that can be almost unique. An approach that helps to structure the problem and focus on the most impactful measures is a promising approach to extend and facilitate decision making when implementing energy efficiency measures in industrial domain.

Since industrial decision-making is driven by cost-benefits analysis, the presented approach should include economical analysis to be smoothly accepted by decisionmakers. This aspect is already under consideration and will be integrated in the approach within future developments.

\section{Acknowledgment}

This research is partially funded by the European Commission under the $7^{\text {th }}$ Framework Programme - research project EMC²-Factory (www.emc2-factory.eu).

\section{References}

1. Fischer, J.; Weinert, N.; Herrmann, C.: Method for selecting improvement measures for discrete production environments using an extended energy value stream model. Submitted to 12th Global Conference on Sustainable Manufacturing. Johor Bahru, Malaysia, Sep 2014.

2. Posselt, G.; Fischer, J.; Heinemann, T.; Thiede, S.; Alvandi, S.; Weinert, N. et al.: Extending Energy Value Stream Models by the TBS Dimension - Applied on a Multi Product Process Chain in the Railway Industry. Accepted for 21st CIRP LCE Trondheim, June 2014.

3. Weinert, N.; Fischer, J.; Posselt, G.; Herrmann, C.: Lean and Green Framework for Energy Efficiency Improvements in Manufacturing. . In (Seliger, G., Ed.): Proceedings of the 11th Global Conference on Sustainable Manufacturing. Innovative Solutions, 2013; p. 512-516.

4. Fink, R.: A priority rule based multi criteria scheduling framework for energy efficiency aware detailed production planning. In: Proceedings of the 39th IEEE IECON, Vienna, Nov. 2013, pp. $7508-7512$

5. Mose, C.; Weinert, N.: Evaluation of Process Chains for an Overall Optimization of Manufacturing Energy Efficiency, in Advances in Sustainable and Competitive Manufacturing Systems, FAIM 2013, pp. 1639-1651.

6. Mose, C.; Weinert, N.: Process and process chain evaluation for an overall optimization of energy efficiency in manufacturing - The welding case. In: Robotics and Computer Integrated Manufacturing; accepted for publication.

7. Müller, F.; Cannata, A.; Stahl, B.; Taisch, M.; Thiede, S.; Herrmann, C. Green Factory Planning - Framework and modules for a flexible approach APMS 2013, Volume 414 of IFIP Advances in Information and Communication Technology, Springer, pp. 167-174.

8. Müller, F.; Cannata, A. Integrierte Bewertung als zentraler Bestandteil einer grünen Fabrikplanung. In: Vernetzt Planen und Produzieren 2013. TU Chemnitz 